\title{
Suicides in female prisoners in England and Wales, 1978-2004
}

\author{
Seena Fazel and Ram Benning
}

\section{Summary}

We calculated, in narrow age bands, suicide rates for female prisoners compared with the general population between 1978 and 2004. The standardised mortality ratio (SMR) for suicide was 20.7 (95\% Cl 16.7-25.7), with a higher excess in younger women ( $<25$ years, SMR $=40(95 \% \mathrm{Cl} 29-57) ; \geqslant 25$ years, SMR $=20(95 \% \mathrm{Cl} 15-26))$. There was a trend over time for SMRs to have increased, supporting the need for recent national initiatives for suicide prevention in prisoners

\section{Declaration of interest}

None.
There are over 4000 women imprisoned in England and Wales, and the number has more than doubled in a decade; ${ }^{1}$ women constitute $5-6 \%$ of all prisoners, a proportion that has steadily risen since the 1960s. Studies have reported high rates of mental disorder, $^{2}$ self-harm ${ }^{3}$ and suicide. ${ }^{4}$ However, comparison of suicide rates with the female general population has not been quantified and suicide trends in women prisoners are not reliably known. As suicide rates have changed for women in the general population, with a reduction in age-standardised rates in women aged over $45,{ }^{5}$ comparison is necessary by calendar year and in narrow age-bands. Furthermore, as base rates of suicide are low, an extended period is necessary to study trends. Therefore, we studied suicide mortality among females in English and Welsh prisons between 1978 and 2004 in comparison with age-specific background rates for the general female population.

\section{Method}

Following receipt of approval from the Prison Health Research Ethics Committee, we sought all death certificates of sentenced and remanded female inmates during 1978-1997 from the Medical Research Unit, Office for National Statistics and, for 1998 to 2004, numbers of suicide by age band from the Safer Custody Group, Prison Service, Ministry of Justice. Suicide cases were defined as females with post-mortem findings of suicide (ICD-9 ${ }^{6}$ codes E950-959) or deaths from 'injury undetermined' whether accidentally or purposefully inflicted (ICD-9 codes E980-989), and, in those without a post-mortem (four cases), where the coroner recorded suicide or an open verdict. The total number of females in prison each year was determined from Home Office data using standard methods, and the average annual population was calculated. ${ }^{4}$ Standardised mortality ratios (SMRs) were calculated according to standard Prison Service age banding: $14-16,17-20,21-24,25-29,30-39,40-49$ and 50+ years from 1978 to 1989 , with the first two groups changed to $15-17$ and 18-20 from 1990. General population death rates for suicide were requested from the Office for National Statistics to correspond to these exact age bands for each year between 1978 and 2004, including the revised age banding from 1990. Trends over time were calculated over 5 -year periods using linear regression with $\log$ transformed SMR on time period. The model assumptions were explored using residual analysis and diagnostic plots. Information on all-cause mortality was available for the period 1978-1997, and an overall SMR was estimated using methods previously described. ${ }^{7}$ We also calculated SMRs by two larger age-bands ( $<25$ years and $\geqslant 25$ years). Information on social class, estimated from last occupation recorded on death certificates was available for only ten prison suicides and not analysed further. We included an additional analysis to take into account the expected number of suicides based on the high prevalence of opioid dependence. ${ }^{8}$ For this analysis, we assumed a lifetime prevalence of opioid dependence of $43.5 \%$ (the prevalence of opioid injectors $^{9}$ in the late 1990 s multiplied by 1.5 to infer opioid users, as per previous work $^{8}$ ). As this assumes that the prevalence of opioid dependence has been unchanged during 1978-2004, we estimated expected suicide in two alternative models that assumed lower prevalences in the first 15 years of two-thirds (i.e. 29\%) and a half (i.e. $22 \%$ ).

\section{Results}

Between 1978 and 2004, 83 suicides in female prisoners were recorded (online Table DS1): 163 suicides per 100000 prisoners. The SMR for suicide at all ages was 20.7 (95\% CI 16.7-25.7). Age-specific SMRs were calculated. There were no suicides in prisoners under 18 years. In those aged 18-20 years, the SMR was 70 (95\% CI 44-113); 37 (95\% CI 23-58) in those 21-24 years; 27 (95\% CI 17-43) in those 25-29 years; 17 (95\% CI 10-27) in those $30-39$ years; 22 (95\% CI $12-38$ ) in those $40-49$; and 8 (95\% CI $2-$ 33 ) in those aged over 50 . When larger age-bands were used, those $<25$ years had an SMR of 40 (95\% CI 29-57) compared with those $\geqslant 25$ years, who had an SMR of 20 (95\% CI 15-26). There was a significant increase in SMRs over this time period (regression coefficient $(\beta)=0.37, t=9.41$, d.f. $=5, P>0.001$; Fig. 1$)$. This did not change when the last time period (2003-2004) was excluded from the analysis $(\beta=0.32, t=8.16$, d.f. $=4, P=0.004)$.

For the subanalysis of all-cause mortality from 1978 to 1997 (including deaths from natural causes in addition to suicide), 43 deaths in custody were analysed. All-cause SMR was $3.0(95 \%$ CI 2.3-4.1) and suicides constituted $60.5 \%$ of the deaths. The SMR for natural causes of death (i.e. excluding suicide, homicide and accidents) was 1.6 (95\% CI 1.0-2.6). There were insufficient numbers to calculate the cause-specific SMRs.

When opioid dependence was accounted for, ${ }^{8}$ the annual number of expected suicides was 0.30 compared with 3.07 actual suicides per year over 1978-2004 (equivalent to $S M R=10.2$ ). If a lower prevalence of opioid dependence in the first 15 years was assumed, the annual numbers of expected suicides were 0.26 (if prevalence was $29 \%$ in the earlier years) and 0.23 (if prevalence was $22 \%$ in the earlier years, equivalent to $\mathrm{SMR}=13.3$ ). 


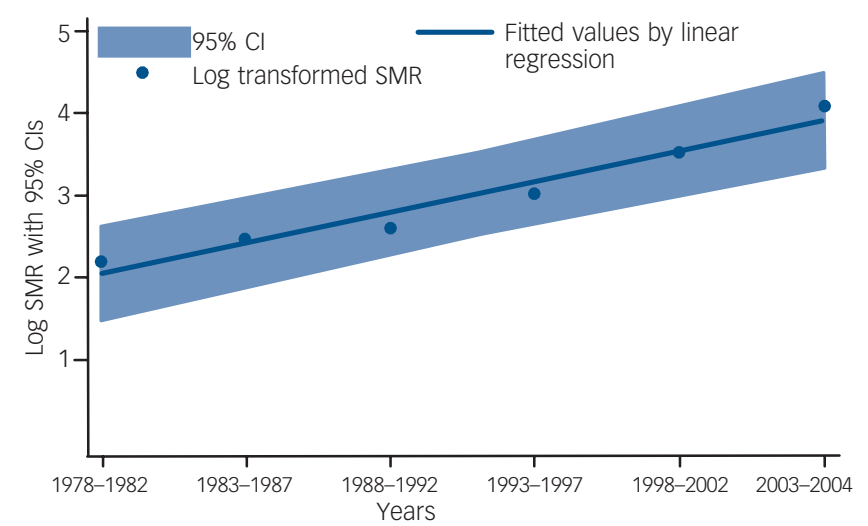

Fig. 1 Trend over time for SMRs for suicide in female prisoners 1978-2004. SMR, standardised mortality ratio.

\section{Discussion}

For the past 25 years, suicide has been about 20 times more common in female prisoners in England and Wales than in the general female population of similar ages. This excess has been increasing steadily over recent decades and is more than the fivefold increase in SMR for suicide found in male prisoners. ${ }^{10}$ Female prisoners aged $<25$ years had higher SMRs than older inmates. The highest SMR in male prisoners was for the youngest age group (15-17 years). ${ }^{10}$ Together, these findings suggest that younger prisoners are a particularly high-risk group. The strengths of this study include its long duration and the careful comparison with general population suicide rates by narrow age-bands and by calendar year.

The higher overall SMR for female prisoners compared with male prisoners highlights a gender gap in suicide that has also been found in recently discharged prisoners ${ }^{11}$ but is less pronounced in psychiatric patients. In psychiatric patients, the male to female ratio of suicides is 2:1 compared with $3: 1$ in the general population. ${ }^{12}$ The gender gap does not appear to be present in the SMR for all-cause mortality: in male prisoners, over the same time period, all-cause mortality SMR was $2.9,{ }^{7}$ compared with 3.0 reported here. One possible explanation for higher SMR for suicide in female prisoners is that females entering prison may have higher prevalences of risk factors associated with suicide, such as depression, ${ }^{2}$ previous self-harm and history of physical and sexual abuse. Substance misuse is a risk factor for prison suicides, ${ }^{13}$ and a systematic review has shown that the relative excess of substance misuse in prisoners compared with the general population is higher for female inmates. ${ }^{14}$ Another explanation is that prison may specifically increase the vulnerability of females to suicide. The impact of custody on women with dependent children, to take one example, may be relevant. ${ }^{15}$

Although social class information was limited, such differences are unlikely to explain the SMR for suicide reported social classes. ${ }^{16}$ Some of the suicide excesses seen among prisoners may relate to characteristics before imprisonment, such as psychiatric illness and substance misuse. ${ }^{2,14}$ The increased mortality of opioid users, reported to be ten times the general population, ${ }^{17}$ accounted for about half the SMR. The reasons for the increasing SMR for prison suicide are likely to be complex. One possible explanation is that the above-average increase in the number of women convicted of drug-related offences ${ }^{18}$ may have led to increasing numbers of females entering prison with substance use problems. Our findings underscore the current national strategy to reduce risk in key high-risk groups such as prisoners and to reduce the availability and lethality of methods. ${ }^{19}$ Further work, including investigations of near-lethal suicide attempts ${ }^{20}$ and case-control studies of prisoners, ${ }^{13}$ is necessary to clarify the contribution of prison-related variables such as overcrowding, distance from the prisoner's home, length of time served and the proportion of pre-sentenced females, and provide information on other potentially modifiable risk factors.

Seena Fazel, MD, MRCPsych, University of Oxford, Department of Psychiatry, Warneford Hospital, Oxford; Ram Benning, MRCPsych, Derby City Hospital, UK

Correspondence: Dr Seena Fazel, University of Oxford, Department of Psychiatry, Warneford Hospital, Oxford OX3 7JX, UK. Email: seena.fazel@psych.ox.ac.uk

First received 18 Oct 2007, final revision 21 Jul 2008, accepted 27 Aug 2008

\section{Acknowledgements}

This study was funded by Oxfordshire Health Services Research Committee. We are grateful to Michael Keene from the Safer Custody Group for assistance with the data, Professor Keith Hawton and Dr Lisa Marzano for helpful discussions, Professor John Danesh for methodological advice and Louise Linsell for statistical assistance.

\section{References}

1 National Offender Management Service. Population in Custody Quarterly Brief. April to June 2005 England and Wales. Home Office, 2005.

2 Fazel S, Danesh J. Serious mental disorder in 23000 prisoners: a systematic review of 62 surveys. Lancet 2002; 359: 545-50.

3 Jenkins R, Bhugra $\mathrm{D}$, Meltzer $\mathrm{H}$, Singleton $\mathrm{N}$, Bebbington $\mathrm{P}$, Brugha $\mathrm{T}$, et al. Psychiatric and social aspects of suicidal behaviour in prisons. Psychol Med 2005; 35: 257-69.

4 Shaw J, Baker D, Hunt IM, Maloney A, Appleby L. Suicide by prisoners: national clinical survey. Br J Psychiatry 2004; 184: 263-7.

5 Gunnell D, Middleton N. National suicide rates as an indicator of the effect of suicide on premature mortality. Lancet 2003; 362: 961-2.

6 World Health Organization. International Classification of Diseases and Related Health Problems (ICD-9). WHO, 1978.

7 Fazel S, Benning R. Natural deaths in male prisoners: a 20-year mortality study. Eur J Public Health 2006; 36: 441-4.

8 Gore SM. Suicide in prisons: reflection of the communities served, or exacerbated risk? Br J Psychiatry 1999; 175: 50-5.

9 Weild AR, Gill ON, Bennett D, Livingstone SJ, Parry JV, Curran L. Prevalence of HIV, hepatitis B, and hepatitis C antibodies in prisoners in England and Wales: a national survey. Comm Dis Public Health 2000; 3: 121-6.

10 Fazel S, Benning R, Danesh J. Suicides in male prisoners in England and Wales, 1978-2003. Lancet 2005; 366: 1301-2.

11 Pratt $D$, Piper $M$, Appleby $L$, Webb $R$, Shaw J. Suicide in recently released prisoners: a population-based cohort study. Lancet 2006; 368: 119-23.

12 National Confidential Inquiry. Avoidable Deaths: Five Year Report of the National Confidential Inquiry into Suicide and Homicide by People with Mental IIIness. University of Manchester, 2006.

13 Fazel S, Cartwright J, Norman-Nott A, Hawton K. Suicide in prisoners: a systematic review of risk factors. J Clin Psychiatry 2008; e1-11 (pii: ej07r03949)

14 Fazel S, Bains $\mathrm{P}$, Doll $\mathrm{H}$. Substance abuse and dependence in prisoners: a systematic review. Addiction 2006; 101: 181-91.

15 Mackenzie N, Oram C, Borrill J. Self-inflicted deaths of women in custody. $\mathrm{Br}$ J Forensic Practice 2003; 5: 27-35.

16 Saunderson $T$, Haynes $R$, Langford I. Urban-rural variations in suicides and undetermined deaths in England and Wales. J Public Health Med 1998; 20: 261-7.

17 Harris EC, Barraclough B. Excess mortality of mental disorder. Br J Psychiatry 1998; 173: 11-53.

18 Councell R. The Prison Population in 2002. A Statistical Review. TSO (The Stationery Office), 2003.

19 Department of Health. National Suicide Prevention Strategy for England. TSO (The Stationery Office), 2002

20 Marzano L, Rivlin A, Fazel S, Hawton K. Interviewing survivors of near-lethal self-harm: a novel approach for investigating suicide amongst prisoners. J Forensic Legal Med 2008; doi: 10.1016/j.jflm.2008.08.011. 